\title{
EKSPLORASI DAN PERBANYAKAN JAMUR TRICHODERMA SP. SEBAGAI BAHAN PEMBUATAN FUNGISIDA HAYATI DI DESA WATAS
}

\author{
Ahmad Saleh ${ }^{1}$, Ari Saputra ${ }^{2}$, Fiken Yamida ${ }^{2}$, M. Raflenchyo ${ }^{2}$, Nikolaus Derry Chandra ${ }^{2}$, N.A. \\ Regata Satya Dewi ${ }^{2}$, Nira Syahara Putri ${ }^{2}$, Novia Nisa Salsabila ${ }^{2}$ \\ ${ }^{1}$ Jurusan Ilmu Hukum, Fakultas Hukum, Universitas Lampung \\ Penulis Korespodensi : noviasalsa11@gmail.com
}

\begin{abstract}
Abstrak
Tingginya intensitas penyakit tanaman akibat jamur patogen di Desa Watas menjadikan penggunaan fungisida sintetik sebagai cara yang umum untuk mengatasi masalah tersebut. Penggunaan fungisida sintetis yang tidak tepat bisa menjadi bahaya jangka panjang, terutama jika digunakan terus menerus. Program Pengendalian Hama Terpadu (PHT) yang diprakarsai oleh pemerintah menyerukan penggunaan fungisida sintetis sebagai upaya terakhir dan disarankan untuk menggunakan jenis fungisida lain seperti fungisida biologis. Jamur Trichoderma sp. merupakan salah satu mikroorganisme yang dapat digunakan sebagai fungisida hayati oleh masyarakat Desa Watas. Program pendidikan dan pelatihan masyarakat tentang cara menggali, memperbanyak dan membuat fungisida hayati dari cendawan Trichoderma sp. kemudian dilakukan di Desa Watas bersama kelompok tani. Program kerja yang dilaksanakan oleh mahasiswa Pengabdian kepada Masyarakat Universitas Lampung Periode I tahun 2021 ini bertujuan untuk memberikan wawasan kepada para petani di Desa Watas tentang bagaimana cara memproduksi fungisida hayati secara mandiri sebagai solusi yang aman dan tepat untuk pengendalian penyakit tanaman menuju sistem pertanian yang berkelanjutan. Petani Desa Watas sangat antusias mengikuti program ini dan berharap dapat mengaplikasikannya dalam proses budidaya.
\end{abstract}

Kata kunci: Fungisida Hayati, Trichoderma sp., Pengendalian Hama Terpadu

\begin{abstract}
The high intensity of plant disease due to pathogenic fungi in Watas Village makes the use of synthetic fungicides a common way to overcome this problem. Improper use of synthetic fungicides can be a long-term hazard, especially if used continuously. The Integrated Pest Management (IPM) program initiated by the government calls for the use of synthetic fungicides as a last resort and is recommended to use other types of fungicides such as biological fungicides. The fungus Trichoderma $s p$. is one of the microorganisms that can be used as a biological fungicide by the people of Watas Village. Community education and training programs on how to explore, propagate and manufacture biological fungicides from the fungus Trichoderma sp. then carried out in Watas Village with the farmer groups. The work program carried out by the University of Lampung Community Service Period I students in 2021 aims to provide insights to farmers in Watas Village about how to independently produce biological fungicides as a safe and appropriate solution to controlling plant diseases towards a sustainable agricultural system. Watas Village Farmers are very enthusiastic about participating in this program and hope to apply it in the cultivation process.
\end{abstract}

Keywords: Biological Fungicide, Trichoderma sp., Integrated Pest Management 


\section{Jurnal Pengabdian Kepada Masyarakat BUGUH}

Dipublikasikan

Badan Pelaksana Kuliah Kerja Nyata

Universitas Lampung

Sekretariat Badan Pelaksana Kuliah Kerja Nyata, Universitas Lampung. Jl. Prof. Dr. Scemantri Brojonegoro No. 1, Bandar Lampung 35145.

\section{Pendahuluan}

Lampung Barat merupakan suatu kabupaten di Provinsi Lampung yang sejak dahulu sudah dikenal sebagai sentra produk hortikultura. Salah satu desa penghasil produk hortikultura adalah Desa Watas yang terletak di Kecamatan Balik Bukit. Desa Watas atau Pekon (bahasa Lampung : desa) Watas merupakan salah satu desa terluas yang ada di Kecamatan Balik Bukit. Salah satu pekerjaan utama masyarakat Desa Watas adalah petani hortikultura. Menurut Buchori dkk. (2020), terdapat beberapa faktor yang menjadi pembatas produksi produk hortikultura di Kabupaten Lampung Barat seperti faktor genetis atau varietas tanaman, modal, manajemen agribisnis, dan juga perubahan iklim yang berdampak langsung kepada berubahnya pola interaksi makhluk hidup pada agroekosistem misalnya serangan organisme pengganggu tanaman (OPT). Organisme Pengganggu Tumbuhan (OPT) merupakan salah satu faktor pembatas penting dalam upaya peningkatan produksi sayuran. Serangan OPT terjadi disemua tahap pengelolaan agribisnis sayuran dimulai dari sebelum masa tanam, di pertanaman, sampai penyimpanan dan pengangkutan produk. Gangguan OPT dianggap kendala terpenting karena untuk menanggulanginya petani biasanya menggunakan pestisida yang dianggap satu-satunya cara tercepat dan paling efektif untuk mempertahankan hasil panennya. Pestisida bagi petani pada umumnya dianggap sebagai jaminan produksi, sehingga penggunaannya cenderung kurang bijaksana dengan jumlah dan jenisnya yang berlebihan.

Identifikasi lapang mendapati bahwa salah satu jenis pestisida yang marak digunakan oleh petani di Desa Watas adalah fungisida, atau golongan pestisida yang diperuntukkan mengendalikan jamur patogen tumbuhan. Penggunaan fungisida ini tidak lain karena intensitas penyakit tanaman yang disebabkan jamur patogen cukup tinggi. Penyakit-penyakit tanaman yang menurut para petani dapat menyebabkan kerugian cukup tinggi antara lain penyakit layu fusarium, busuk batang, cacar daun, rontoh bunga dan buah, serta "mati gadis" atau dumping off. Intensitas penyakit tanaman yang tinggi tentu berkorelasi positif dengan letak geografis Desa Watas yang berada di perbukitan sehingga memiliki kelembaban dan curah hujan yang tinggi yang menjadikan penyebaran serta perkembangan spora jamur patogen juga seringkali tidak dapat dikendalikan. Jika sudah seperti ini maka penggunaan fungisida sintetik menjadi pilihan yang banyak dilakukan petani karena dianggap lebih efektif dan efisien disamping penggunaannya yang relatif praktis. Penggunaan fungisida harus bijak dan ditempatkan sesuai fungsinya, pengunaan fungisida sintetik yang tinggi atau pemakaian fungisida secara berlebihan justru akan menimbulkan resistensi patogen atau mikroorganisme parasit yang menjadi kebal terhadap fungisida dan juga pengunaan fungisida sitentik terus menerus tidak baik bagi ekosistem, akibatnya fungisida menjadi tidak efektif.

Pengendalian Hama Terpadu (PHT) menjadi salah satu program pemerintah yang digalakkan untuk terwujudnya sistem pertanian berkelanjutan agar dapat menopang kebutuhan pagan umat manusia di masa depan. Salah satu hal penting dalam PHT adalah penggunaan pestisida sintetik apapun jenisnya menjadi sangat terbatas, digunakan apabila benar-benar diperlukan saja dan dalam jumlah yang terbatas. Pengendalian lainnya seperti secara kultur teknis, pengendalian fisik, dan pengendalian biologi menjadi teknik yang lebih didahulukan atau diprioritaskan. Sayangnya banyak petani yang khususnya di Desa Watas yang belum memahami hal tersebut dan malah menggunakan fungisida sintetik sejak awal tanam dengan alasan pencegahan atau tindakan pengendalian preventif. Padahal pengendalian preventif terutama yang berkaitan langsung dengan perlakuan terhadap tanaman dapat dilakukan dengan pengendalian biologi mislanya penggunaan fungisida hayati. Fungisida hayati adalah fungisida yang mengandung mikroorganisme sebagai agens pengendali hayati sehingga tidak memanfaatkan bahan aktif. Fungisida hayati sangat baik terutama bagi keberlangsungan ekosistem karena tidak menimbulkan resistensi pada target sasaran dan juga relatif lebih aman karena tidak meninggalkan residu berupa bahan kimia berbahaya pada produk pertanian. Lebih dari itu, fungisida hayati adalah ciri dari sebuah pengendalian organisme pengganggu tanaman yang berkelanjutan. 


\section{Jurnal Pengabdian Kepada Masyarakat BUGUH}

Dipublikasikan

Badan Pelaksana Kuliah Kerja Nyata

Universitas Lampung

Sekretariat Badan Pelaksana Kuliah Kerja Nyata, Universitas Lampung. Jl. Prof. Dr. Scemantri Brojonegoro No. 1, Bandar Lampung 35145.

Jamur Trichoderma sp. adalah salah satu jenis jamur antagonis yang dapat digunakan sebagai fungisida hayati bagi tanaman. Jamur ini telah banyak diuji efetivitasnya dalam mengendalikan jamur patogen tumbuhan. Hartal dkk. (2010) melaporkan jamur Trichoderma sp. merupakan agen antagonis yang cukup efektif untuk menghambat perkembangan patogen Fusarium oxysporum yang merupakan penyebab penyakit layu pada tanaman krisan. Selain itu jamur ini juga mampu menyediakan unsur hara tanaman yang diperlukan untuk mendukung pertumbuhan organ vegetatif maupun reproduktif melalui proses dekomposisi bahan organik yang diberikan pada media tanam. Efri dkk. (2010) juga melaporkan bahwa jamur Trichoderma sp. yang diisolasi dari filosfer tanaman jagung memiliki kemampuan antagonisme yang baik terhadap isolat jamur patogen Phytophthora capsici. Soesanto dkk. (2013) melakukan percobaan daya hambat jamur Trichoderma sp. yang diisolasi dari perakaran tanaman terhadap beberapa isolat jamur patogen seperti Fusarium sp., Phytophthora sp., Colletotrichum capsici, Pythium sp., dan Sclerotium rolfsii. Hasilnya jamur Trichoderma sp. yang diuji memiliki daya penghambatan yang baik terhadap semua jenis isolat jamur patogen secara in vitro. Oleh karena itu maka pelatihan dan pendidikan masyarakat mengenai jamur antagonis Trichoderma sp. di Desa Watas dirasa sangat diperlukan terutama karena kemampuannya sebagai pengendali jamur patogen dan dapat diisolasi dari perakaran tanaman sehingga berpotensi dijadikan fungisida hayati yang baik untuk mengatasi masalah penyakit tanaman di Desa Watas.

\section{Bahan dan Metode}

Pelaksanaan program ini dimulai dengan persiapan pada tanggal 13 Februari hingga pelatihan pada 19 Februari pukul 13.30 WIB s.d 16.00 WIB di Dusun Bayur, Desa Watas, Kecamatan Balik Bukit, Kabupaten Lampung Barat. Metode yang digunakan yaitu pelatihan dan pendidikan masyarakat dengan cara menghadirkan perwakilan kelompok tani dari setiap dusun yang juga turut dibantu dan dikoordinir oleh ketua GAPOKTAN Desa Watas, kemudian melakukan simulasi mengenai tahapan cara memperoleh jamur Trichoderma sp. dari alam sekitar, beserta penjelasan terkait manfaat, cara penggunaan, kelebihan serta kekurangannya. Program ini juga membuka sesi berbagi pengalaman para petani mengenai permasalahan penyait tanaman yang disebabkan jamur patogen dan bagaimana penanganannya menggunakan jamur antagonis Trichoderma sp. sebagai fungisida hayati.

Berikut ini ada beberapa bahan yang perlu disiapkan yaitu $0,5 \mathrm{~kg}$ beras, satu ruas bambu beserta bukunya di kanan dan kiri, tali rafia, lilin, plastik bening ketebalan 0,5, nasi yang sudah didiamkan semalam, dan air. Kemudian ada beberapa alat penunjang yaitu sendok atau spatula inokulasi, kardus bekas yang telah dibersihkan, stapler, dan arit.

Di dalam pelaksanaanya terdapat beberapa tahapan yaitu tahapan persiapan inokulum jamur Trichoderma sp., perbanyakan Trichoderma sp. pada media beras, dan pelaksanaan kegiatan. Inokulum jamur antagonis Trichoderma sp. diperoleh dengan cara melakukan "pemancingan" jamur Trichoderma pada perakaran bambu. Caranya yaitu dengan membelah ruas bambu menjadi 2 bagian, kemudian di bagian buku kanan dan kiri dibuat lubang sebesar jari kelingking. Setelah itu dimasukkan nasi yang telah didiamkan selama semalam (12 jam) sebanyak 3-4 sendok makan di salah satu belahan bambu. Kemudian, belahan bambu berisi nasi tersebut ditutup dengan belahan bambu pasangan sebelumnya dan diikat menggunakan tali palstik seperti tali rafia agar tidak terpisah. Bambu tersebut kemudian dipendamkan pada perakaran bambu maksimal sedalam $20 \mathrm{~cm}$ menggunakan arit. Setelah 5-6 hari, bambu diangkat dan diidentifikasi jamur pada nasi dalam bambu, jika berwarna kehijauan atau keputihan menuju hijau maka jamur tersebut bisa dikatakan sebagai jamur Trichoderma sp. Dengan demikian "pemancingan" berhasil. 


\section{Jurnal Pengabdian Kepada Masyarakat BUGUH}

Dipublikasikan

Badan Pelaksana Kuliah Kerja Nyata

Universitas Lampung

Sekretariat Badan Pelaksana Kuliah Kerja Nyata, Universitas Lampung. Jl. Prof. Dr. Scemantri Brojonegoro No. 1, Bandar Lampung 35145.

\section{Hasil dan Pembahasan}

Program pelatihan ini merupakan salah satu program kerja KKN Universitas Lampung Periode I Tahun 2021 yang dilaksanakan di bidang pertanian. Sebagai salah satu sektor yang banyak dijadikan mata pencaharian masyarakat Desa Watas, tentu terdapat kendala selama dilakukan praktik budidaya pertanian. Berdasarkan analisis lapang, salah satu kendala utamanya adalah intensitas penyakit tanaman yang seringkali tinggi terutama penyakit-penyakit tanaman yang disebabkan oleh jamur patogen. Hal ini menjadikan petani sering kewalahan dan menggunakan cara cepat pengendalian yaitu menggunakan fungisida sintetik. Penggunaan fungisida sintetik yang tidak tepat dan berlangsung secara terus menerus tentu berdampak buruk bagi keberlanjutan pertanian di Desa Watas karena berpotensi menrusak ekosistem. Penggunaan fungisida sintentik yang sudah lumrah bukan semata-mata petani yang ingin cara cepat saja, namun juga dikarenakan minimnya pengetahuan mengenai jenis fungisida lain yang jauh lebih ramah lingkungan, salah satunya fungisida hayati dari jamur antagonis Trichoderma sp.. Program kerja ini mengadaptasi program nasional yang juga termasuk dalam SDG's (Sustainable Development Goals) yaitu pertanian berkelanjutan atau sustainable agriculture. Sistem pertanian berkelanjutan ini digunakan untuk mengurangi kerusakan lingkungan, mempertahankan produktivitas pertanian, meningkatkan pendapatan petani serta meningkatkan stabilitas dan kualitas kehidupan masyarakat di pedesaan. Menurut Efendi (2016), tiga indikator besar yang dapat dilihat adalah lingkungannya lestari, ekonominya meningkat (sejahtera), dan secara sosial diterima oleh masyarakat petani.

Jamur Trichoderma sp. merupakan salah satu jenis jamur tanah yang memiliki kemampuan antagonisme terhadap jamur lain yang umumnya bersifat parasit tumbuhan. Jamur ini dapat diisolasi pada perakaran tanaman bambu yang tentunya banyak ditemukan di sekitaran Desa Watas. Warnanya yang hijau gelap atau warna-warna serupa yang mendekati hijau, menjadikan jamur ini mudah untuk diamati oleh banyak orang tanpa harus melakukan uji lebih lanjut. Jamur "sahabat petani" ini bisa menjadi salah satu solusi dalam mengendalikan penyakit tanaman terutama secara preventif. Banyak petani di Desa Watas mengeluhkan beberapa jenis peyakit seperti layu fusarium, antraknosa, cacar daun, dan "mati gadis" atau dumping off pada pertanaman hortikultura mereka. Penyakit-penyakit tersebut umumnya disebabkan karena beberapa faktor seperti pola tanam yang tidak melakukan rotasi, cuaca yang lembab dan sejuk, serta penggunaan fungisida hayati yang dapa menyebabkan resistensi pada jamur patogen. Jamur Trichoderma sp. dilaporkan dapat menghambat pertumbuhan jamur Sclerotium rolfsii Sacc. penyebab layu pada tanaman cabai di Maluku (Uruilal dkk., 2017).

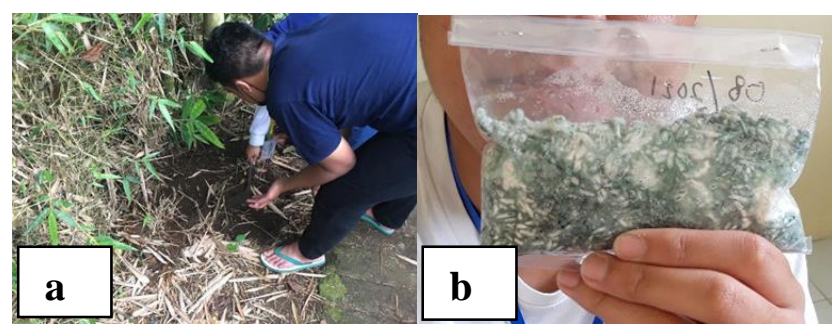

Gambar 1. (a) proses "pemancingan" (eksplorasi) jamur Trichoderma sp. pada perakaran bambu di Desa Watas; (b) Jamur Trichoderma sp. yang berhasil diisolasi dan dibiakkan pada media nasi setengah matang.

Keuntungan yang didapatkan dari penggunaan jamur Trichoderma sp. sebagai agensia hayati tentunya sangat baik jika diimplementasikan di Desa Watas. Walaupun tanah di desa ini tergolong masih subur dan dapat dilihat dari tanahnya yang hitam, namun belum tentu tanah tersebut merupakan tanah yang sehat. Tanah yang sehat adalah tanah yang memiliki kepadatan populasi mikroorganisme bermanfaat yang tinggi. Mikroorganisme dari kelompok jamur mungkin saja sudah berkurang dikarenakan penggunaan fungisida sintetik yang berlebih dan tidak didasarkan pada prinsip pengendalian hama terpadu (PHT). Kegiatan pengabdian ini dilakukan di salah satu rumah warga di Dusun Bayur dan juga dihadiri oleh salah satu 


\section{Jurnal Pengabdian Kepada Masyarakat BUGUH}

Dipublikasikan

Badan Pelaksana Kuliah Kerja Nyata

Universitas Lampung

Sekretariat Badan Pelaksana Kuliah Kerja Nyata, Universitas Lampung.

Jl. Prof. Dr. Scemantri Brojonegoro No. 1, Bandar Lampung 35145.

pendamping pertanian di Desa Watas. Kegiatan ini berisikan simulasi cara eksplorasi, aplikasi dan juga cara perbanyakan jamur Trichoderma sp. yang mudah serta sederhana. Simulasi dilakukan dengan turut menyertakan prototipe atau model berupa ruas bambu yang berisi nasi penuh hifa Trichoderma sp. dan juga jamur yang sudah dibiakkan dalam media nasi setengah matang. Pembagian materi berupa prosedur rinci tahapan pembuatan dan eksporasi jamur ini juga dilakukan agar peserta dapat kembali mempelajarinya di rumah. Setelah dilakukan simulasi kemudian dilakukan tanya jawab serta sharing atau berbagi pengalaman seputar penyakit tanaman serta pengendaliannya.

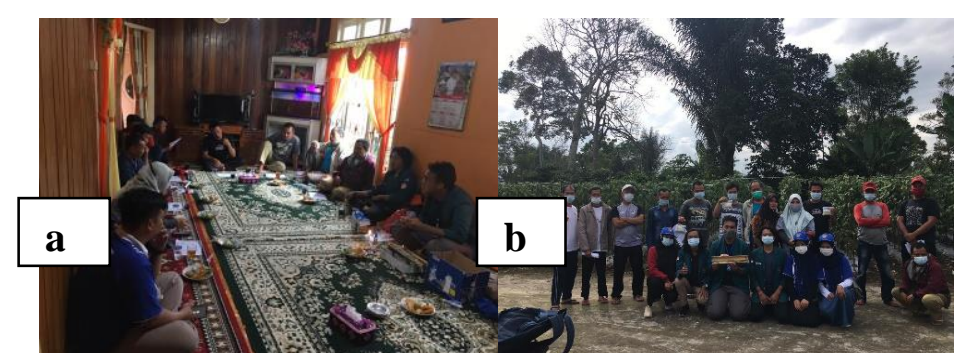

Gambar 2. (a) Suasana pelatihan bersama perwakilan kelompok tani di Desa Watas; (b) Foto bersama panitia dan peserta usai kegiatan pelatihan pembuatan fungisida hayati.

Kelemahan dari pengendalian menggunakan agensia hayati semacam ini juga turut disampaikan bahwasanya hanya dapat dilakukan sebagai tindakan pencegahan dan mungkin efektivitas dari fungisida hayati ini dapat berbeda di satu tempat dengan tempat yang lainnya. Hal ini dikarenakan fungisida hayati menggunakan jasad hidup yang berarti sangat peka terhadap faktor-faktor lingkungan yang tentu dapat mempengaruhinya. Petani dan juga penyuluh pertanian yang hadir dalam acara tersebut mengatakan bantuan Trichoderma sp. pernah dibagikan oleh pemerintah kepada para petani namun dalam kemasan. Petani tidak mengetahui cara eksplorasi atau pembuatannya yang ternyata relatif mudah dan sederhana. Pelatihan semacam ini tentunya sangat diperlukan dan sangat disambut baik oleh para petani. Bukan tidak mungkin jika pelaksanaan kegiatan dilakukan bukan pada saat pandemi COVID-19, maka peserta yang datang akan ramai. Sejatinya para petani adalah orang-orang yang senang belajar sehingga bukan sebuah wacana menjadikan petani sebagai seorang ahli PHT yang menjadi kunci pertanian berkelanjutan. Petani dan masyarakat umum harus sadar apa bahaya pengguanaan pestisida khususnya fungisida jika pengaplikasiannya tidak tepat. Kita harus sadar bahwa apa yang kita ambil dari alam harus kita kembalikan lagi ke alam. Tanah-tanah yang ditanami sekarang harus tetap dapat ditanami di masa depan karena kebutuhan akan pangan adalah hal mutlak untuk umat manusia. Petani-petani yang cerdas pada akhirnya akan memahami betapa pentingnya memperhitungkan berapa banyak produksi yang dapat diselamatkan untuk masa depan, bukan sekedar berapa banyak yang dapa dihasilkan saat ini.

Selama pelaksanaan program kerja ini tidak ada kendala yang berarti, terlebih lokasi desa yang tidak begitu jauh dengan tempat tinggal. Protokol kesehatan juga disiapkan bersama-sama seluruh anggota kelompok dan warga setempat. Warga Desa Watas sangat ramah dan sangat antusias mempelajari teknologi baru. Sepanjang pelaksanaanya kami selalu dibimbing dan diarahkan untuk berdiskusi memecahkan permasalahan yang ada di Desa Watas terutama masalah pertanian. Tidak jarang setelah program ini dilakukan para petani yang bertemu dengan mahasiswa KKN mengajak untuk melihat keadaan kebun dan berdiskusi langsung di kebun. Petani tersebut akan memperkenalkan mahasiswa kepada para petani yang lainnya untuk ikut berbagi cerita serta pengalaman di bidang pertanian. Kebersamaan semacam ini tentu tidak dapat dialami semua orang. Namun siapapun yang mau terjun dan memberikan ilmu yang didapat di bangku perkuliahan akan mengalaminya. Tidak jarang teori yang diajarkan di perguruan tinggi tidak dapat secara langsung diimplementasikan ke lapangan, misalnya terkait fungisida hayati yang mungkin memiliki efektivitas yang

Vol 1 No 22021 


\section{Jurnal Pengabdian Kepada Masyarakat BUGUH}

Dipublikasikan

Badan Pelaksana Kuliah Kerja Nyata

Universitas Lampung

Sekretariat Badan Pelaksana Kuliah Kerja Nyata, Universitas Lampung. Jl. Prof. Dr. Scemantri Brojonegoro No. 1, Bandar Lampung 35145.

rendah jika diaplikasikan di lapangan. Mungkin inilah yang menyebabkan istilah "teori dan praktik itu berbeda", memang mungkin berbeda tapi tidak sepenuhnya. Tugas para mahasiswa adalah untuk memberi pemahaman yang baik kepada para petani bahwa tidak ada pengendalian patogen penyebab penyakit tanaman yang sederhana. Petani Desa Watas diharapkan dapat menjadi perintis untuk perubahan pola pikir masyarakat. Mulai bergerak menggunakan agensia hayati seperti jamur Trichoderma sp. sebagai fungisida hayati yang relatif lebih ramah lingkungan dan menunjang keberlanjutan sistem pertanian khususnya di Desa Watas.

\section{Kesimpulan}

Program pelatihan ini merupakan salah satu program kerja KKN Universitas Lampung Periode I Tahun 2021 yang dilaksanakan di bidang pertanian. Sebagai salah satu sektor yang banyak dijadikan mata pencaharian masyarakat Desa Watas, tentu terdapat kendala selama dilakukan praktik budidaya pertanian. Salah satu kendala utamanya adalah intensitas penyakit tanaman yang seringkali tinggi terutama penyakit-penyakit tanaman yang disebabkan oleh jamur patogen. Hal ini menjadikan petani sering kewalahan dan menggunakan cara cepat pengendalian yaitu menggunakan fungisida sintetik, fungisida hayati yang digunakan dari jamur antagonis Trichoderma sp. Program kerja ini mengadaptasi program nasional yang juga termasuk dalam SDG's (Sustainable Development Goals) yaitu pertanian berkelanjutan atau sustainable agriculture. Sistem pertanian berkelanjutan ini digunakan untuk mengurangi kerusakan lingkungan, mempertahankan produktivitas pertanian, meningkatkan pendapatan petani serta meningkatkan stabilitas dan kualitas kehidupan masyarakat di pedesaan.

Jamur Trichoderma sp. merupakan salah satu jenis jamur tanah yang memiliki kemampuan antagonisme terhadap jamur lain yang umumnya bersifat parasit tumbuhan. Jamur ini dapat diisolasi pada perakaran tanaman bambu yang tentunya banyak ditemukan di sekitaran Desa Watas. Keuntungan yang didapatkan dari penggunaan jamur Trichoderma sp. sebagai agensia hayati tentunya sangat baik jika diimplementasikan di Desa Watas. Walaupun tanah di desa ini tergolong masih subur dan dapat dilihat dari tanahnya yang hitam, namun belum tentu tanah tersebut merupakan tanah yang sehat. Kegiatan pengabdian ini dilakukan di salah satu rumah warga di Dusun Bayur dan juga dihadiri oleh salah satu pendamping pertanian di Desa Watas. Kegiatan ini berisikan simulasi cara eksplorasi, aplikasi dan juga cara perbanyakan jamur Trichoderma sp. yang mudah serta sederhana. Simulasi dilakukan dengan turut menyertakan prototipe atau model berupa ruas bambu yang berisi nasi penuh hifa Trichoderma sp. dan juga jamur yang sudah dibiakkan dalam media nasi setengah matang. Pembagian materi berupa prosedur rinci tahapan pembuatan dan eksporasi jamur ini juga dilakukan agar peserta dapat kembali mempelajarinya di rumah. Setelah dilakukan simulasi kemudian dilakukan tanya jawab serta sharing atau berbagi pengalaman seputar penyakit tanaman serta pengendaliannya.

Namun kelemahan dari pengendalian menggunakan agensia hayati semacam ini juga turut disampaikan bahwasanya hanya dapat dilakukan sebagai tindakan pencegahan dan mungkin efektivitas dari fungisida hayati ini dapat berbeda di satu tempat dengan tempat yang lainnya. Hal ini dikarenakan fungisida hayati menggunakan jasad hidup yang berarti sangat peka terhadap faktor-faktor lingkungan yang tentu dapat mempengaruhinya. Sejatinya para petani adalah orang-orang yang senang belajar sehingga bukan sebuah wacana menjadikan petani sebagai seorang ahli PHT yang menjadi kunci pertanian berkelanjutan. Petani dan masyarakat umum harus sadar apa bahaya pengguanaan pestisida khususnya fungisida jika pengaplikasiannya tidak tepat. Kita harus sadar bahwa apa yang kita ambil dari alam harus kita kembalikan lagi ke alam. Tanahtanah yang ditanami sekarang harus tetap dapat ditanami di masa depan karena kebutuhan akan pangan adalah hal mutlak untuk umat manusia. Petani-petani yang cerdas pada akhirnya akan memahami betapa pentingnya memperhitungkan berapa banyak produksi yang dapat diselamatkan untuk masa depan, bukan sekedar berapa banyak yang dapa dihasilkan saat ini.

Vol 1 No 22021 


\section{Jurnal Pengabdian Kepada Masyarakat}

\section{BUGUH}

Dipublikasikan

Badan Pelaksana Kuliah Kerja Nyata

Universitas Lampung

Sekretariat Badan Pelaksana Kuliah Kerja Nyata, Universitas Lampung. Jl. Prof. Dr. Scemantri Brojonegoro No. 1, Bandar Lampung 35145.

\section{Ucapan Terima Kasih}

Terimakasih kami ucapkan kepada seluruh masyarakt Desa Watas, Kecamatan Balik Bukit, Lampung Barat atas antusias yang luar biasa sehingga kegiatan ini dapat berjalan dengan baik. Tak lupa kami ucapkan terimakasih juga kepada Bapak Mirwan Atmaja, A.Md. selaku Kepala Desa dan seluruh aparatur Desa Watas yang telah mengizinkan kami untuk melaksanakan Kuliah Kerja Nyata di Desa Watas. Kami berharap berbagai kegiatan yang telah kami laksanakan dapat bermanfaat bagi seluruh masyarakat Desa Watas.

\section{Daftar Pustaka}

Efendi, E. (2016). Implementasi Sistem Pertanian Berkelanjutan dalam Mendukung Produksi Pertanian. Jurnal Warta, Vol 47.

Uruilal, C., Talahaturuson, A., Rumahlewang, W., dan Patty, J. (2017). Isolasi Trichoderma spp. dan Daya Antagonismenya terhadap Sclerotium rolfsii Sacc. Penyebab Penyakit Layu pada Tanaman Cabai

(Capsicum annuum) Secara in Vitro. Jurnal Budidaya Pertanian, Vol 13(2): 64-67.

Buchori., Prasetiyo, E. Y., dan Mardiono, T. (2020). Analisis Perbedaan Pendapatan Petani Cabai Kemitraan Indofood Dengan Petani Gurem Di Kecamatan Balik Bukit, Kabupaten Lampung Barat. Jurnal Fidusia, Vol 3(1): 1-14.

Hartal., Misnawaty, dan Budi, I. (2010). Efektivitas Trichoderma sp. dan Gliocladium sp. dalam Pengendalian Layu Fusarium pada Tanaman Krisan. Jurnal Ilmu-Ilmu Pertanian Indonesia, Vol 12 (1): 7-12.

Efri., Prasetyo, J. dan Suharjo, R. (2010). Skrining dan Uji Antagonisme Jamur Trichoderma Harzianum yang Mampu Bertahan di Filosfer Tanaman Jagung. Jurnal Hama dan Penyakit Tumbuhan Tropika, Vol 9(2): 121-129.

Soesanto, L., Mugiastuti, E., Rahayuniati, R.F., dan Dewi, R.S. (2013). Uji Kesesuaian Empat Isolat Trichoderma spp. dan Daya Hambat In Vitro terhadap Beberapa Patogen Tanaman. Jurnal Hama dan Penyakit Tumbuhan Tropika, Vol 13(2): 117-123. 